\title{
Study of Archaeological Sites with Imagery: A Case on Narsingdi Region, Bangladesh
}

\author{
Tanjinul Hoque Mollah ${ }^{1, *}, J^{\prime}$ natul Ferdaush ${ }^{2}$, Sharmin Shishir $^{3}$, Xiao Kun ${ }^{1}$, Md Shahedur Rashid ${ }^{4}$ \\ ${ }^{1}$ Graduate School of Letters, Hokkaido University, Japan \\ ${ }^{2}$ Department of Urban Studies and Planning Program, Savannah State University, USA \\ ${ }^{3}$ Graduate School of Environmental Earth Science, Hokkaido University, Japan \\ ${ }^{4}$ Department of Geography \& Environment, Jahangirnagar University, Bangladesh
}

Copyright $\bigcirc 2016$ by authors, all rights reserved. Authors agree that this article remains permanently open access under the terms of the Creative Commons Attribution License 4.0 International License

\begin{abstract}
Ancient historical illustrations are the main introduction of any area which develops the civilization, cultural importance of the region. Wari is the most important archaeological illustration which enriches the history, culture of the surroundings of Bangladesh. As a riverine country continuous cyclone, river bank erosion, flood, landslide and other natural disasters have altered our ancient civilization since the beginning. For this reason many enriched ancient civilization and culture have engraved by rivers and our ancient arts, culture and civilization are ruined. Currently the major problem of archaeological sites is that there is no geo-spatial database prepared so far. This study therefore, is attempted to prepare a geo-spatial database on archaeological sites like Wari Bateshwar region to develop metadata, relevant information and geo-tagged photos having spatial references to fulfill the purpose of exploring and surveying archaeological sites as well as to develop a methodological framework which documents physical and cultural aspects. Primary data have been used for this study was collected through mainly field observation, interviewing and GPS survey according to predesigned information collection sheet. In this study, total 52 archaeological sites have been identified where only two are recognized by government and rests of them are unrecognized. Satellite navigation data and remote sensing imagery were also integrating with the information collection sheet. Detailed metadata and geo-tagged photos on the each archaeological site contains spatial references has been developed which will help understanding further work on archaeological sites. The govt., academic departments and the NGOs should come forward to fulfill the recommendations in the study.
\end{abstract}

Keywords Archaeological Illustration, Engraved, Geo-spatial Database, Geo-tagged Photos

\section{Introduction}

According to Archeologists Wari-Bateshwar is one of the oldest civilizations in Bangladesh. This area is very important for our history and heritage. Human habitation at Wari-Bateshwar has perhaps started around 2500 years ago. This civilization has developed around the Koyra river valley, this river is one of the distributaries of the Old Brahmaputra River [2] [7]. Wari and Bateshwar villages, located in the Narsingdi district, have opened a new chapter of our unknown pre-history through its rich collection of artifacts and cultural heritage. Various precious archaeological resources have found from these villages which reflects the pre-history of our ancient Bengal [1]. It is believed that the region had enriched settlements as a trade centre among the eastern Comilla and Moynamati region and north-eastern Mymensing and Sylhet region due to the Meghna-Brahmaputra confluences of the Ancient Bengal. Many river channels and hillocks of red soil have made a vast diversity of crop production for the then agrarian society [9]. At present the valley has been silted up gradually. Koyra was the common meeting place of Brahmaputra and Meghna Rivers flows from the northern side of ancient Bengal. Probably this place was considered as a river port [9]. Before getting the detailed overviews, we should know the general topography of the region.

\subsection{Topography of the Area}

Being a part of the Madhupur tract, the general topography of the area are mainly divided into three major types- (a) Koyra valley: flood vulnerable, low lying area mainly used for agriculture, water based communication during rainy season; (b) Chala or Terrace land: relatively high land, flood free; mainly uses for settlement/habitation and limited agriculture; and (c) Byde: this area was mainly used for agriculture and communication as well as transportation. [8] Google earth image shows (figure 1) the topography of the study area where generally bright objects reflect the low-lying areas (i.e. valley and bydes) and scatteredly distributed dark objects indicates homestead 
vegetation's (located on chala lands).[3][4]

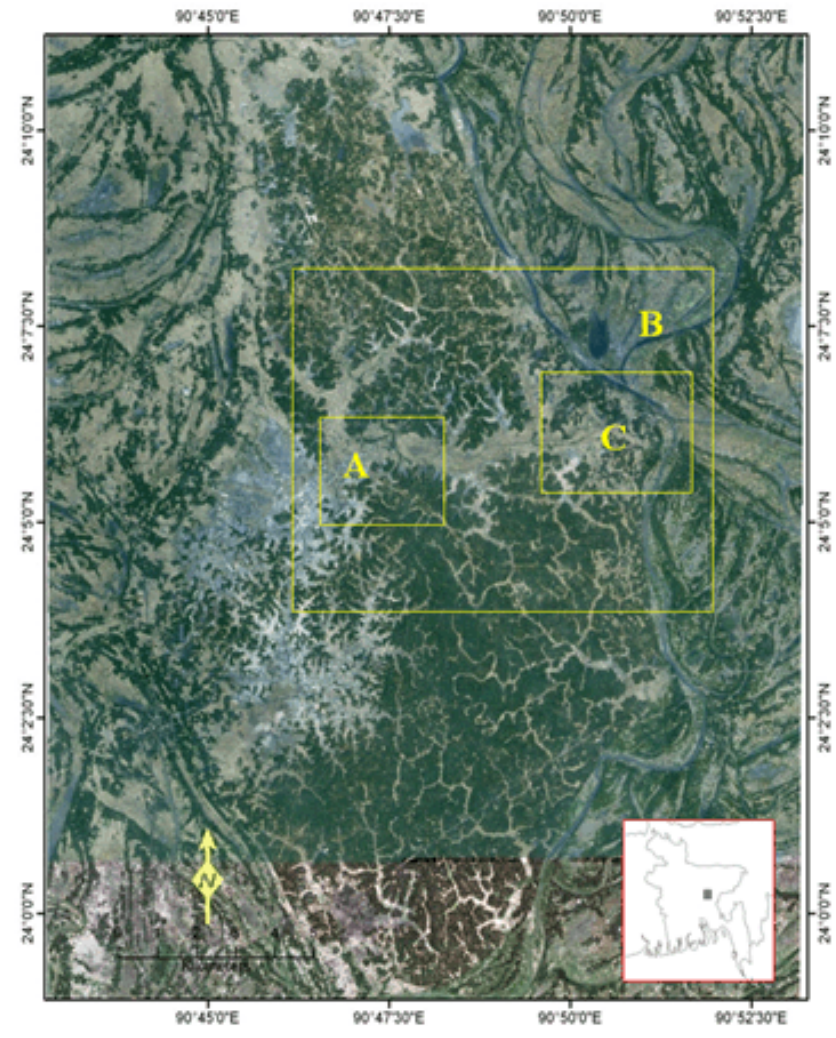

Figure 1. Google Earth image illustrates the greater study region while 'Boxes A, B, and C' are enlarged in figures 1.2, 1.3, and 1.4 accordingly. Inset Bangladesh map shows the location of the Study Area

\subsection{Contextualizing Koyra River}

It is very important to know that growth of any civilization depends upon its overall context and surrounding environs of the particular region. The study area also possesses very important parameters that helped building the Wari-Bateshwar territory. Google earth image generally gives such a great glimpse and an overview. Interpreting figure 2, the Koyra River's context can be summarized as below:

A) Due to geological formation lateral erosion of silty-clay soil is limited thereby river sifting is uncommon like other flood plain rivers.

B) Intense, dissected topography of the terrace provide silt through run-off which eventually silted up the valley as a consequence the river Koyra gradually become a narrow channel.

C) River shifting has not taken place due to intense sifting up the primary valleys (1st and 2 nd order streams) have been transformed into agricultural land.

Based on the ground survey, observation and satellite image interpretation, it shows that the Wari-Bateshwar area has been subjected t0o an upliftment along the Belabo bazar (steep river bank- an indication of a fault line), causing cut off the Koyra river mouth from the main channel. [10]
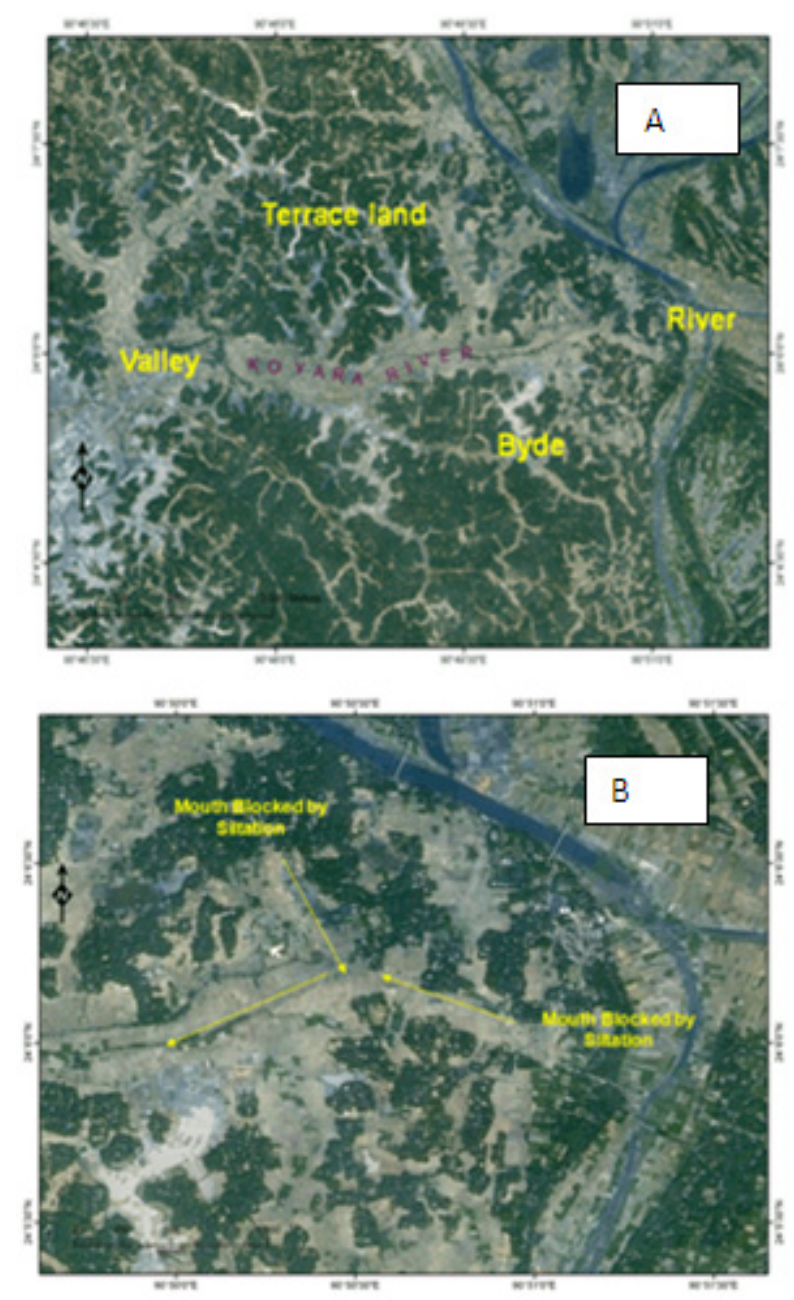

Figure 2. Contextualizing Koyra River (A and B)

There are some important issues to be discussed here that the approaches of geographic and archaeological studies, application of satellite remote sensing and aerial photos in archaeology, freely availability of Google Earth imagery are interlinked in understanding the perspectives of the study. The following sections highlight the issues briefly. [5][6]

\subsection{Aim and Objectives}

The Aim of this paper is to study of archaeological sites and imagery. In this context, the specific objectives of the study are given the following:

A) To explore and survey the each archaeological site using satellite image

B) Documentation physical aspects on archaeological sites with GPS data.

\subsection{Commonality between Archaeological and Geographical Methods}

On the archaeological methods three are most important. These are: survey, excavation and analysis. A modern archaeological project often beings with a survey. Regional survey is an attempt to systematically locate previously unknown sites in a region. Sites survey on the other hand, is 
an attempt to systematically locate features of interest, such as houses and maidens (i.e. mound of domestic refuse), within a site. Each of these two goals may be accomplished with largely the same methods. Survey work has many benefits if performed as a preliminary exercise to or even in place of excavation. Although surveying a large region or sites can be expensive it is the only way to gather some forms of information such as settlement patterns and settlement structure. Survey data are commonly assembled into maps which may show surface features and/or artifact distribution [11]. The commonality between geographical and archaeological methods rests primarily on the approaches and methods of survey. Both regional and site survey requirements of archaeology would be fulfilled by the same survey methods as employed in geographical survey, including use of aerial photographs and satellite imageries coupled with such traditional ground survey techniques as plane table, prismatic compass and theodolite [3].

\subsection{Literature Review}

Wari is one of the significant archaeological sites in Bangladesh. There were many research works and related activities published in newspaper, journal, books etc. which are given below-A school teacher, Mr. Hanif Pathan wrote a note on punch-marked coins, some chance finds, in a Bengali weekly Mohammadi (Pathan 1933). Then on the basis of Pathan's report Curator of Dacca Museum N. K. Bhattasali reported the matter in the annual report of the Dacca Museum (Battashali 1935-36: 5). This report was cited in the history of Bengal Vol. 1 (Majumdar (ed.) 1943:664). Hanif Pathan (Pathan 1955) again discussed punch-marked coins in the Daily Azad. Habibullah Pathan wrote several articles (Pathan, 1970, 1974, 1975, 1978, 1980). He made efforts to earnestly present various antiquities recovered from Wari-Bateshwar and surrounding area and then Montasir Mamun and Habibbullah Pathan wrote respectively 'Bangladesher Itihas Hoito Notun Kore Likhte Hobe' and 'Brahmaputra Savvatar Kendravumi Wari-Bateshwar' in the 'Saaptahik Bichitra' (2nd year, 36 chapters, 21 February 1974). The important publication of Habibullah Pathan is Pratnatattvik Nidarshan: Wari-Bateshwar (1989) in Bengali, the first book ever written on the subject. In 1979 'Bangladesh Archaeology, Number-1' edited by Nazimuddin Ahmed about Wari-Bateshwar. There is a short notice about Wari-Bateshwar in Zakaria's book (Zakaria, 1984). Shafiqul
Asghar (1986) included three articles in Bengali in his anthology Itiha Katha Kao. He published (1992) another article in Narsingdi Itihas. The first professional write-up about Wari-Bateshwar is Dilip K. Chakrabarti's chapter III, in Ancient Bangladesh (1992), based on books by Pathan and Zakaria and his own short field work. Considering the geographical location of Wari-Bateshwar, Chakrabarti assumed that this area maintained contact as entre port with south-east asia and roman world during the early historic period. Chakrabarti also tried to identify (1996) Wari-Bateshwar as Ptolemy's Souanagoura. He further studied a Mauryan amulet from Wari-Bateshwar. Pawankar et al. (1998) attempted to study the chance finds of semiprecious stone beads from Wari-Bateshwar which published in 'Journal of the Asiatic Society of Bangladesh (Vol. 43, No. 2, 1998)'. 'Semi-Precious Stone Beads from Wari-Bateshwar' published in 'Journal of the Asiatic Society of Bangladesh' Rahman S. S. M, et al (1998). Basa and Rahman (1998) wrote 'Bronge Knobbed Bowls from Wari, Bangladesh: Implications for Trade' which published in journal of Bengal Art (Vol. 3, 1998). In 2003 an essay of 'Wari-Bateshware Prapto Kacher Puti: Akti Pratnatattvik Somikkha' published in 'Protnotattbo Journal, Dept. of Archaeology, and JU.

\section{Data Sources, Methods and Study Area}

The primary and secondary data including remotely sensed images are being used in this paper. Using information collection sheet for collection information's of each archaeological site (Figure 3). The study used primary data and secondary source to meet up the objectives of the study. The study mainly depends upon primary data which has been done through FGD, key informants interview, case study and personal observation using GPS technology. Secondary data such as Google earth image, census, districts Maps, upazila maps and union maps were used for detailed analysis of the land use and land type of the each archaeological site. The secondary data and literature helps to identify the each archaeological site for detailed mapping. Instruments like santo level, measuring tape, pole, GPS and digital camera had been used for collecting primary data of archaeological sites. 
$\theta$

Name of Emenerater: Embn

\section{Archarelogical Reate Sensing SITE INFORMATION COLLECTON SHEET}

\section{सक्तिया।}

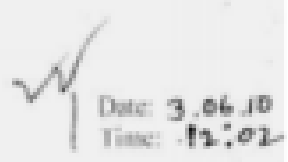

1.8 Geacral Information

tanyabad

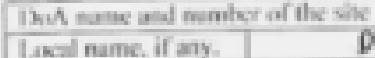

laked name, if any.
\begin{tabular}{l|l|l|l} 
Shost No & Thot No & & Thion \\
\hline
\end{tabular}

2.0 Type of the site

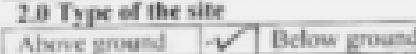

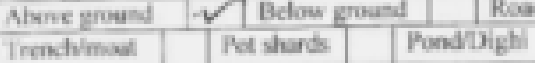

3 A Abolute Lecation of the Cestre Point of the Sile \& Waypeint

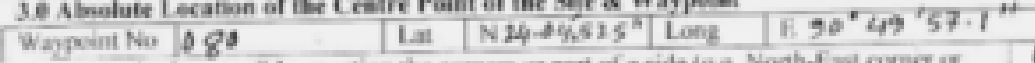

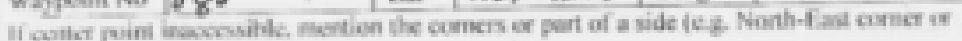

midille of the suath side)

4.e Helative Learaties of Salc, nearest distance in $\mathrm{km}$.

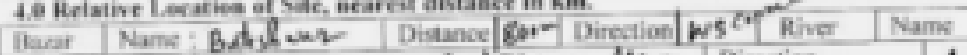

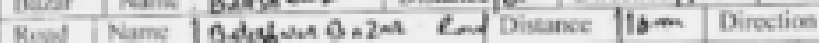

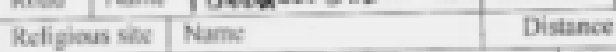

Any other (Nane)

Distance

Diraction

Sa Arrharelegical Status

\begin{tabular}{|l|l|l|l|l}
\hline An cloment of a sile & One unit sile & & Part of a large site eomplex \\
\hline
\end{tabular}

6.0 A pprosinate beight measured from the base of the mound. Use a Suntu level or any other suitable device

$$
4 \% \times 9 r+168 r
$$

\begin{tabular}{|l|l|l|l|l|l|l|}
\hline 7.6 & Appreximate area of the Base of the site. Use a measeriag tape er a red & Area \\
\hline
\end{tabular}

s.o Appresimate shape:

\begin{tabular}{|c|c|c|c|c|}
\hline Syase & Rectangular & Round & Oval & Inczular \\
\hline \multicolumn{5}{|c|}{ 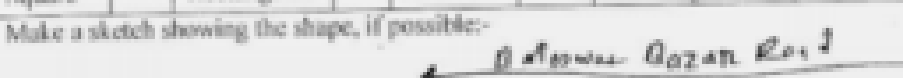 } \\
\hline
\end{tabular}

9.8 Evistieg Iluman Use

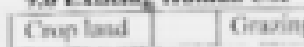

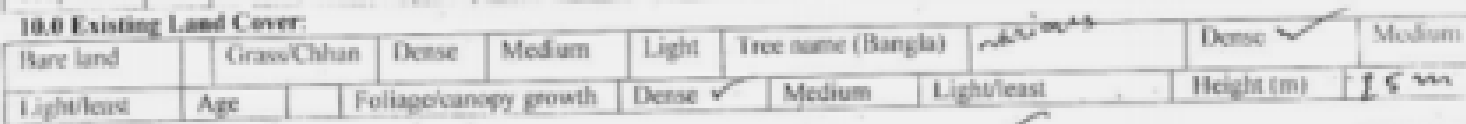

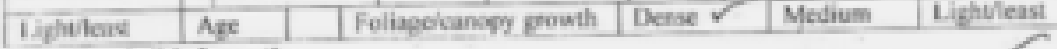

11.9 Tep Sed Informatiea

110 Top Sodinformation

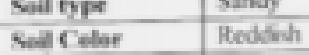

\begin{tabular}{l|l} 
Sell moisere & Dry
\end{tabular}

Oreanie matter High

120 tand typesilecal Tepezraphy

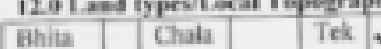

130 Ceaditios of the Site

\begin{tabular}{l|l|l}
\hline Insisturbed & $\begin{array}{l}\text { Modernibely } \\
\text { disturtod }\end{array}$ \\
\hline
\end{tabular}

\begin{tabular}{|l|l|l|}
\hline \multicolumn{1}{|l|}{} & Silty & \\
\hline & Arownish & \\
\hline Moderate & \\
\hline Medium & \\
\hline
\end{tabular}

\begin{tabular}{|l|l|}
\hline Clayey & \\
\hline Biackish & \\
\hline High & \\
\hline low & \\
\hline
\end{tabular}

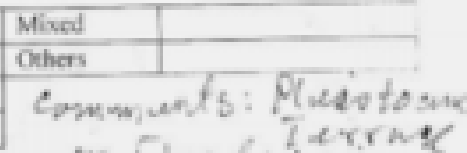

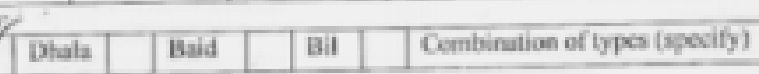

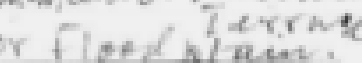

14.0 Degree of Expenere

Highly capored

Moderilely exposed

Largely disturbed

$\checkmark$ Destroyed up to ground leved

Any other

(Plewse specily)

15.0 Sheth of the Ieralify: (ABachment)

16.e Phedegraph:

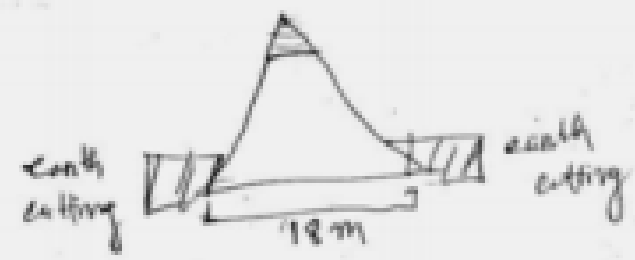

Figure 3. Information's collection sheet 
Metadata of each archaeological site divided into two major categories. These are

A) General information

B) Observation location information

General information is such information which can be found without field observation while secondary data sources are available. On the other hand observation location information is such information which can be found from the field survey that means it contains primary information's. All place names follows according to 1961 census. In the table place names added with Bangla name (Figure 7). Bangla names also follow according to 1961 census. Mouza names collected from the field survey. Period of each archaeological site follows according to Department of Archaeology, Jahangirnagar University.

Raster data is commonly obtained from google images. Google images datasets don't normally contain spatial reference information (either embedded in the file or as a separate file). With aerial photography and satellite imagery, sometimes the locational information delivered with them is often inadequate, and the data does not align properly with other data we may have. Thus, in order to use some raster datasets in conjunction with our other spatial data, we often need to align it or georeference - it to a map coordinates system.

A map coordinate system is defined using a map projection (a method by which the curved surface of the earth is portrayed on a flat surface). When we georeference our raster dataset, we define its location using map coordinates and assign a coordinate system. Georeferencing raster data allows it to be viewed, queried, and analyzed with other geographic data. This paper is normally GeoCorrect raster dataset in Geographic Coordinate System (GCS). This is expressed by latitude and longitude.

In the ancient time there was a civilization in the Narsingdi region especially Belabo, Monohordi, Sibpur and Raipura upazila. There are various types of archaeological evidence in this region. Wari is the nucleus of among these areas. Wari archaeological site is a part of madhupur tract which is under Pleistocene terrain. Recently it is assumed that Wari and surroundings contain the precedence of civilization which was 2000-2500 years ago.

The study area of this research is located on the bank of Brahmaputra River which is centre of the surrounding archaeological sites ancient. Recently it has been mentioned that Wari-Bateshwar was the trade centre of Souanagoura which was described by the Greek Geographer Claudius Ptolemy. Firstly, in 1930s Mr. Hanif Pathan (a local school teacher) presented this archaeological site to the society. After that his son Habibulla Pathan presented its importance writing various aspects of it. Then an archaeological excavation has been continuing by Prof. Dr. Sofi Mostafizur Rahman since 2000. Ministry of culture, some organizations, companies and persons individually spread their helps to continue the act of digging. Already dept. of Geology (D U), BUET, University of Asia Pacific, dept. of Geography \&
Environment (JU), Bangladesh Atomic Research Centre has taken part for research.
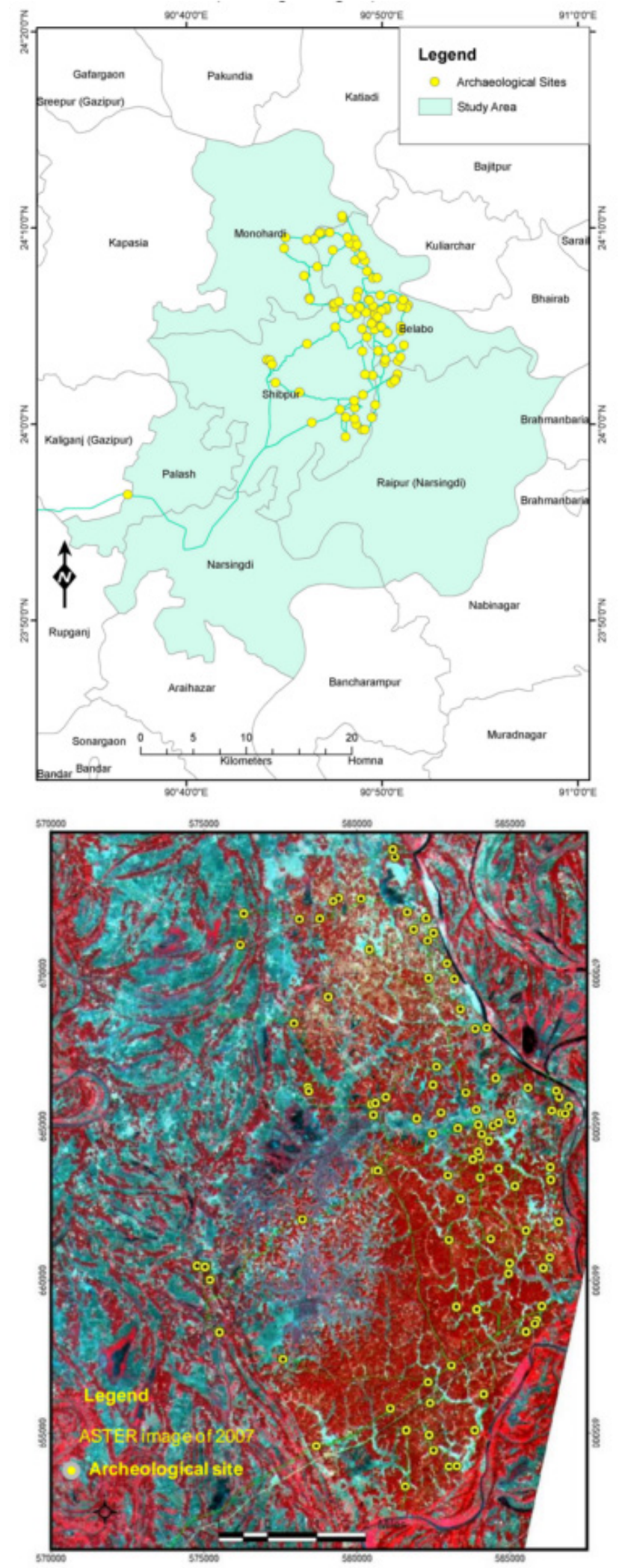

Figure 4. Waypoints (i.e. archaeological sites) and tracts are shown on an upazila map of Narsingdi. Aster image shows each archaeological site which was shown by waypoints. Aster image also shows Vegetation cover, settlements, Road network, byde, canal as well as river. 


\section{Major Findings of the Study}

This research has to be considered pioneer in this field of study as there are wide range of information, maps and data have been integrated and presented. This research mainly focuses of the data development approaches of archaeological sites of Narsingdi including Wari-Bateshwar region using global positioning systems, aerial and satellite imagery, field survey on the same geographic projection methods. Finally a detailed and informative data/map based info-sheet and spatial references have been generated. These references will help researchers, policy makers, tourists and explorers a precise guideline to do further work and relevant activities.

\subsection{Explore and Survey the each Archaeological Site}

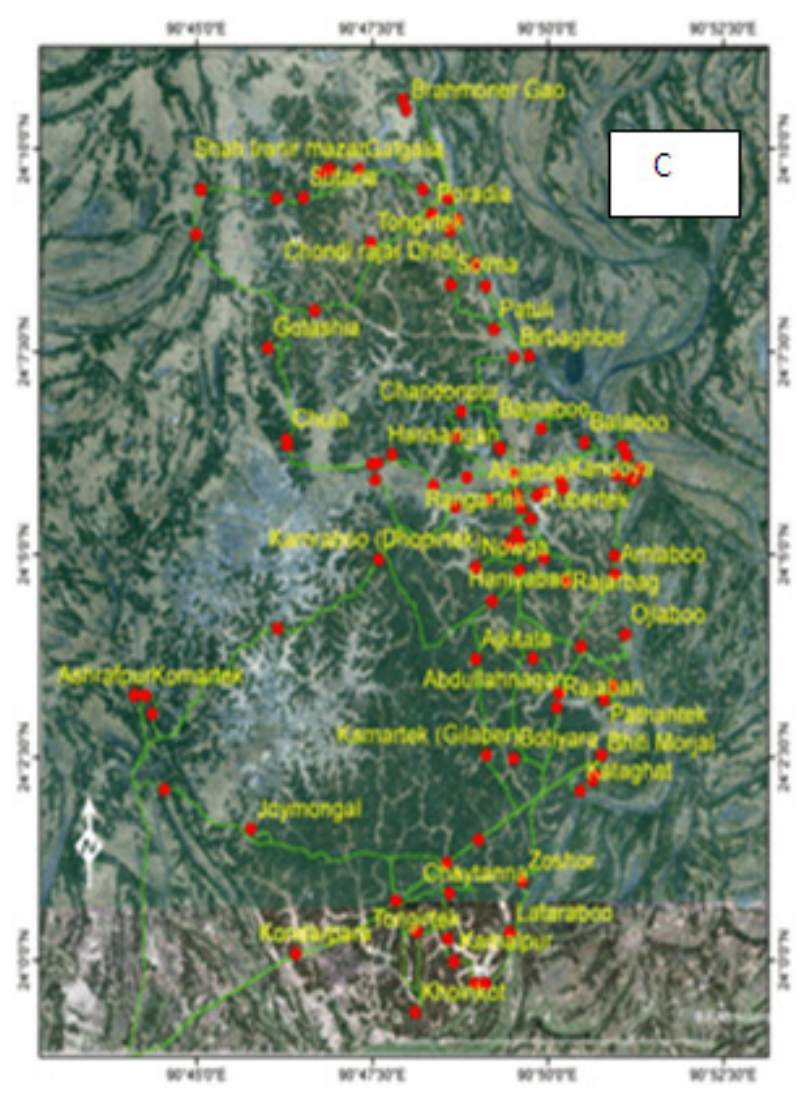

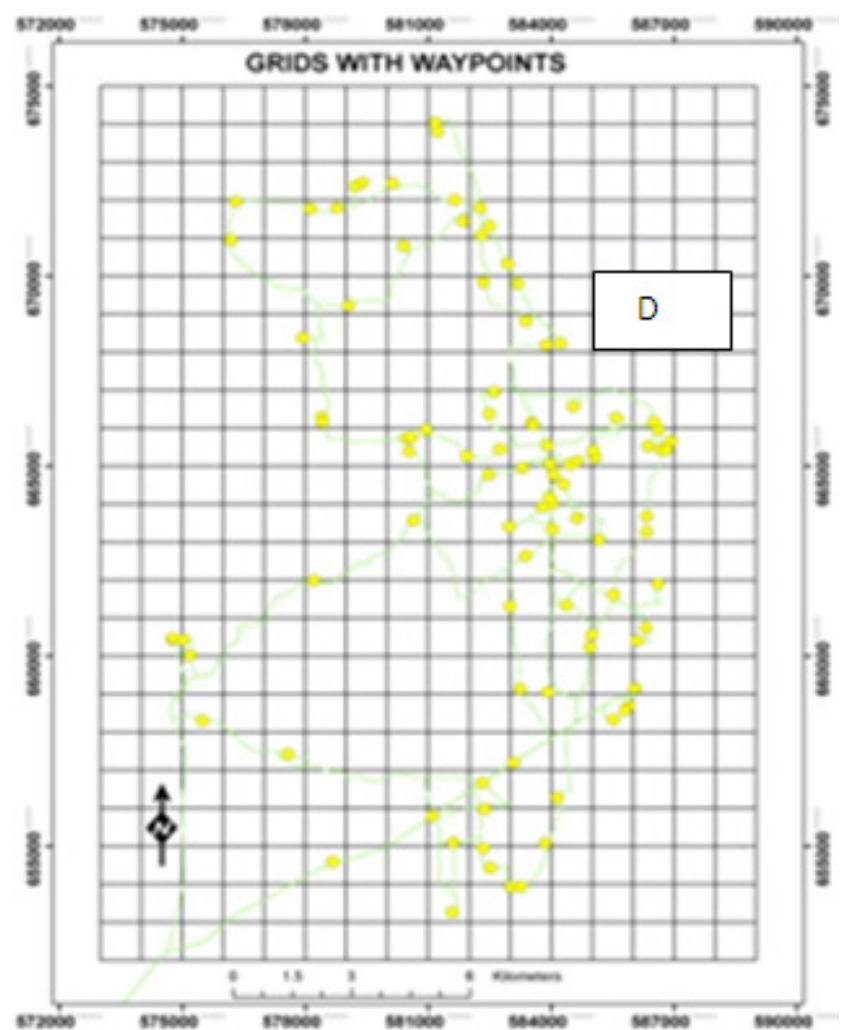

Figure 5. $\mathrm{C}$ and $\mathrm{D}$ shows the archaeological sites of Narsingdi region.

A total of 52 archaeological sites have been explored and discovered in this study. These are mainly located in Belabo (27), Sibpur (17), Raipura (5) and Monohordi (3) upazilas. Noticeably, most of the sites are concentrated in Belabo region where the Wari-Bateshwar fort-town is also located. Integrating GPS coordinates with mouza boundaries are the most important contributions of the research. With the locational data, the concerned GPS routes are also compiled so that the travelers can get easy direction and distance from these datasets. However, the Government has recognized officially only 2 sites out of 52 spots. Others are identified with the help of Department of Archaeology and the Department of Geography and Environment's joint team during conducting the research.

Grids and graticules are the most important part for detailed survey and ID making on each archaeological site. As now satellite navigation data overlapped on grids for the reason that distances calculation from one archaeological site to another.

At a glance it would be easily identify or calculated the distance between two archaeological sites which helps the tourist for their observation purpose. ID generation is very significant for each archaeological site since all. 

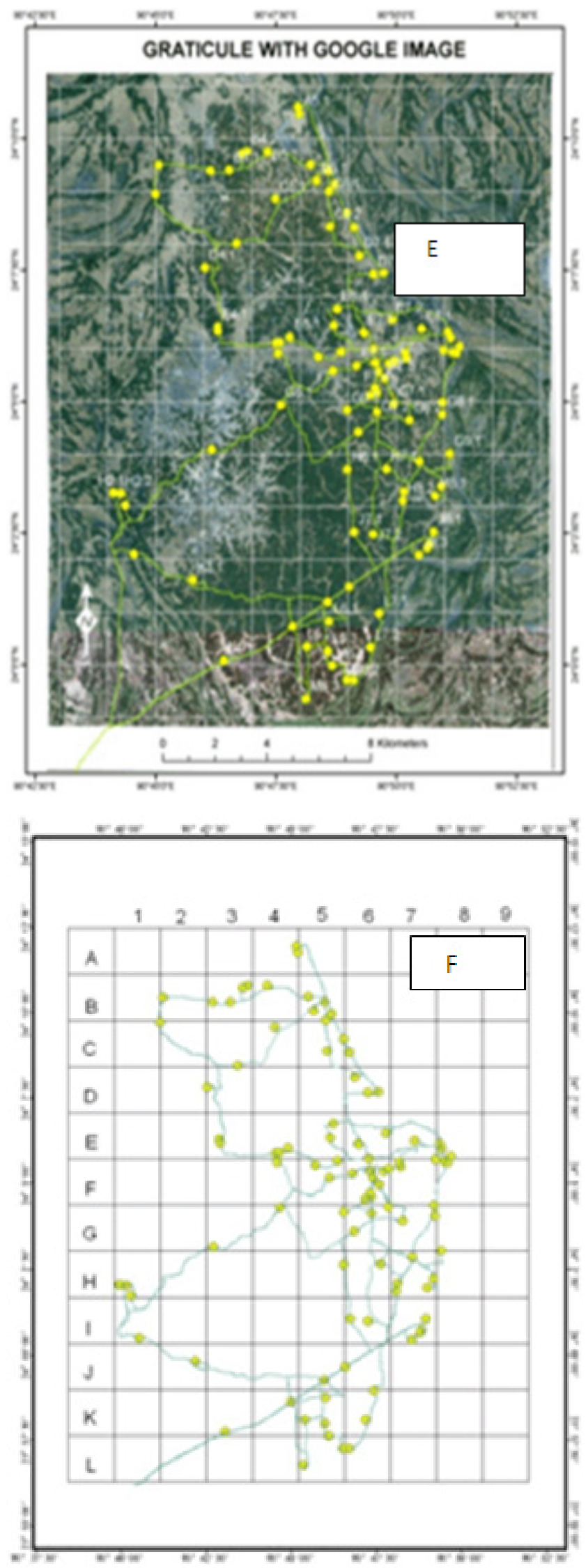

Figure 6. E and $\mathrm{F}$ shows the grids and graticules development approaches of archaeological sites
All archaeological sites were not identified at a same time. It was recognized in different times as a result ID making makes a great problem. This problem was removed by the developing girds and graticules. In the following figure ID making of each archaeological site from the North West (NW) corner. Every rows contain different later such as A, B, $\mathrm{C}, \mathrm{D}$ to $\mathrm{L}$ and every column contain different digit such as $1,2,3,4$ to 9 .

Use of remote sensing technology was the most significant approach in implementing objectives of this study.
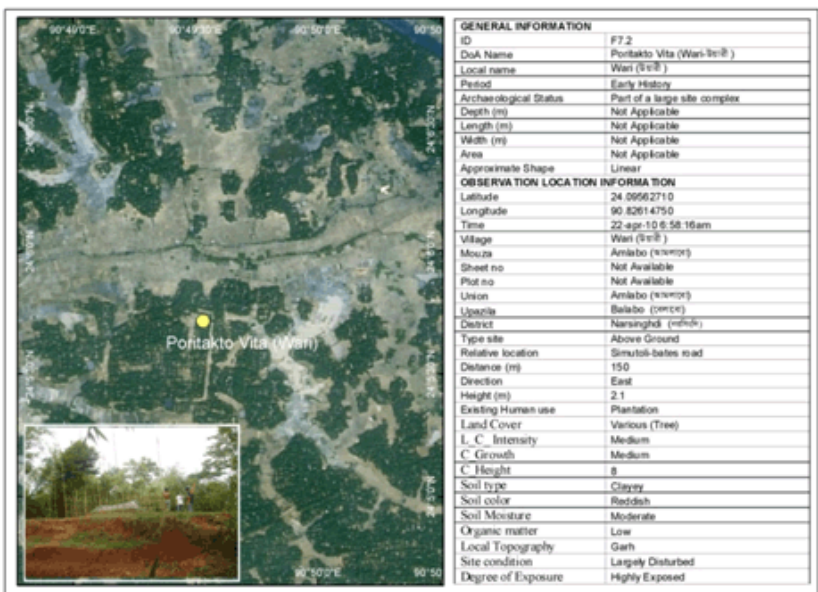

Figure 7. Photos integration with imagery and GPS data

Imagery archives from the Google Earth platform (2015), Aster Satellite Images (2007), Aerial photos (1952) will also help the users to get a clear contextual background of the discovered sites. They variety of remotely sensed imagery will help understanding the different perspectives of the each sites. Historical links and paleo-environment will also be interpreted from these invaluable datasets.

\subsection{Physical Aspects on Archaeological Sites with GPS data}

The physical and cultural features of the area represent the archaeological importance with its historical development with time and space. Its geographical and relative location was the main cause of becoming a fort city during the ancient time. This place was the favorable for building a fort city although there were a boundary/garh and a trench/parikh around the city

Use of Geo-tagged photographs using digital camera are also to be considered as a new dimension and innovative idea in implementing the research goals. All photos are properly geo-referenced and identified with latitude and longitude with WGS-1984 datum. This important integration will help others to make compilation of the characteristics using photo integration tools. Hundreds of photographs with the field verification techniques have been generated and placed in the research accordingly.

The coverage of Digital Maps of Bangladesh using GIS 
methods is also key findings to be considered. In this case, all level administrative maps were overlapped and geo-processed and integrated with field and remotely sensed databases. It was not easy to place all maps in this research due to space problem. A rich GIS datasets are also available to the researcher for further studies. Topographic sheets, mouza/ union/ upazila maps were the main focus primarily to develop info-sheets. All detailed fact sheets are self-explanatory.

In the info-sheets a wide range of parameters have been included, these are mainly: site names (both in Bangla and English), probable historical timelines, heights and lengths, shapes where observation based information have also been tagged such as graticules, administrative hierarchies, relative distance from the key nodes, land use/land cover, soil types, local topographical features. Mainly a framed questionnaire survey has been conducted to collect this information. This information may play a key role in carrying out further research and excavation/ preserving activities by the concerned departments and ministries. These types of info sheet have been developed for the first time in Bangladesh.

Above all, the integration approach was also a unique outcome through this research work, which has helped finally to develop tabular database and geo-tagged metadata having all sorts of graphical evidences and photos. Availability of high resolution satellite image and field photos with basic attributes have been included herewith. All 52 sites are covered and encompassed with proper labeling and text references. Locality names are also included in the images. If any further work to be initiated, these imageries and coordinates will help a clear picture of the in-situ and ex-situ survey work.

\subsection{Summary at a Glance}

A) Locations of the archaeological sites have been clearly identified and explore using remote sensing and GIS technology.

B) Geo-processing and geo-correction the relevant remote sensing imagery and overlapped with satellite navigation data.

C) Developed methodological framework and documentation of physical and cultural aspects on archaeological sites.

D) Develop metadata and detailed inventorying of the site specific geo-spatial information have been documented with unique ID and photo-tagging.
E) A methodological framework between GIS and satellite imagery are formulated.

F) A relatively new branch of archaeological remote sensing is initiated in the context of Bangladesh

G) Total $201.41 \mathrm{~km}^{2}$ is homestead vegetation which is $49.96 \%$ of the total land use of my study area

H) Total $195.41 \mathrm{~km}^{2}$ is low land which is $48.46 \%$ of the total land use of my study area

I) Total $6.38 \mathrm{~km}^{2}$ is river which is $1.58 \%$ of the total land use of my study area

J) A total of 52 archaeological sites have been explored and discovered in this study. These are mainly located in Belabo (27), Sibpur (17), Raipura (5) and Monohordi (3) upazilas.

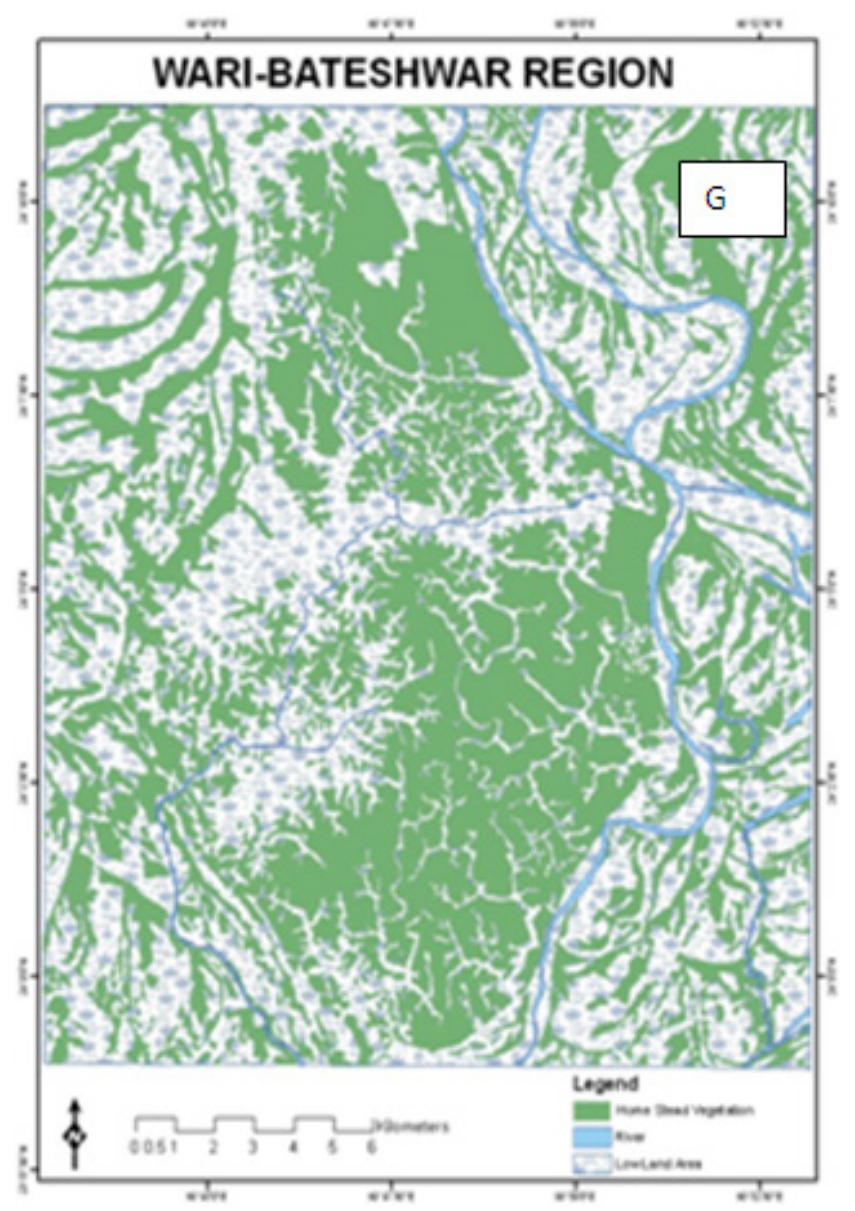




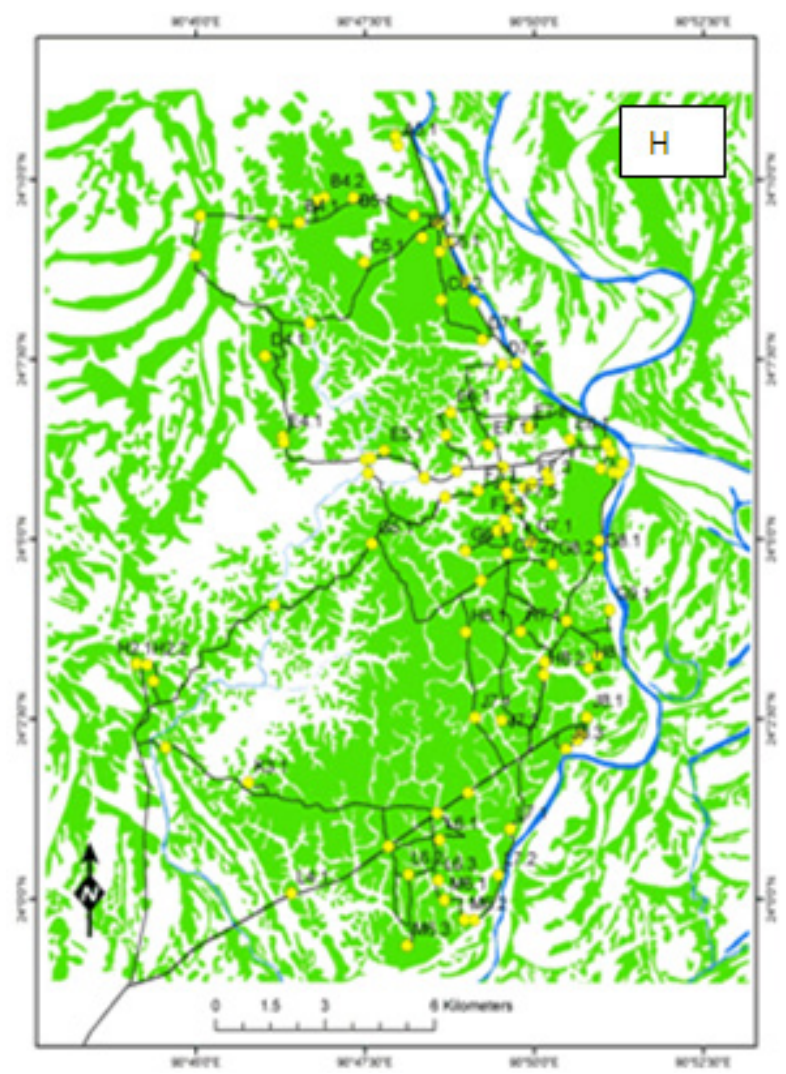

Figure 8. $\mathrm{G}$ and $\mathrm{H}$ shows the land use and land type of archaeological sites

Table 1. Current land use and land type of archaeological sites

\begin{tabular}{|c|c|c|c|c|}
\hline Type & $\begin{array}{c}\text { Area in } \\
\text { Hectares }\end{array}$ & $\begin{array}{c}\text { Area in } \\
\text { Sq km }\end{array}$ & $\begin{array}{c}\text { Total } \\
\text { Area }\end{array}$ & $\begin{array}{c}\text { Percentage } \\
(\%)\end{array}$ \\
\hline $\begin{array}{c}\text { Homestead } \\
\text { Vegetation }\end{array}$ & 20140.73 & 201.41 & & 49.96 \\
\hline Low Land & 19541.16 & 195.41 & \multirow{2}{*}{403.20} & 48.46 \\
\cline { 1 - 2 } River & 637.90 & 6.38 & & 1.58 \\
\hline
\end{tabular}

A) The Government has recognized officially only 2 sites out of 52 spots. Rest of them was identified with the help of Department of Archaeology and the Department of Geography and Environment's joint team during conducting the research.

\subsection{Recommendations}

Therefore, the concerned authority like Dept. of Archaeology, Ministry of Sports and Culture and person, researchers and other organizations should take the appropriate measures immediately to protect this site and surroundings. Following the steps of measures can help the authorities for comprehensive management of land use and reserving the site:

A) First of all, have to concern about the value of our ancient arts, culture and civilization among people.

B) To promote the security of reserving the site and valuable artifacts.

C) The archaeological illustrations are most important to know about our pre-history or ancient Bengal so its importance should present to the public.
D) Need to take appropriate step immediately to protect and reserve this archaeological site.

E) For exploration and developing the historical or temporal data of Wari through GIS and Remote Sensing technology, government should give the funding and man power.

F) Individuals, government and other organizations should take proper care and funding for explorations and excavation activities of Wari and adjacent areas.

\section{Conclusions}

The research is primarily based on the field information where GIS, GPS, satellite photos and Google Earth imagers have played an integrated role. These types of attempt have not been ever attempted before. Through this study, a new frontier of geographic knowledge with interacted with the experiences of archaeological events. By choice and observing field evidences and the researches done by the team of Jahangirnagar Archaeology, this new field will play a role in bridging the gaps between the two major disciplines like geography and archaeology. The state-of-the-art technologies will also be introduced in order to fulfill the clearly mentioned objectives of the study. Moreover, the recommendations to be made will also expose the true history of the glories past the then Bengal, particularly along the valley of Koyra and the adjoining Narshingdi Region where the great civilization more the 2 thousand years old named Wari-Bateshwar empire were disseminated perhaps worldwide. The study was also aimed to trace out the archaeological sites using google image for detailed archaeological survey, both for site survey and regional survey. This paper tried to develop methodological frame work and metadata on each archaeological site and integrating with remote sensing imagery. The study provides that it is possible, with significant accuracy to develop metadata on archaeological sites and these data integrating with remote sensing imagery. For detailed survey and exploration of the archaeological sites will need more sufficient time and money. As of late archaeological sites are destroyed more rapidly because of human activities. If govt. takes proper step then we will be able prevent archaeological sites from the consequences of human aggressive activities.

\section{Acknowledgements}

We would like to thanks department of archaeology, Jahangirnagar University, Savar, Dhaka, Bangladesh and the local communities for their cordial help.

\section{REFERENCES}

[1] Ahammed, Bulbul, 2001, "Narshingdi Zillar Wari-Bateshwar" 
Akti Pratnattava Somiksha, Writer Foundation, Dhaka.

[2] Chakrabarty, Dilip K, 1992, Ancient Bangladesh: A Study of the Archaeological Sources, University Press Limited, Dhaka.

[3] Haque, Enamul, 1996, A Resume of Excavation Report (1956-67), Journal of Bengal Art, Journal of the International Centre for Study of Bengal Art, v-I, pp. 243-262.

[4] Haque, Enamul, Rahman, S. S. Mostafizur \& Ahsan S. M. Kamrul, A Primary Report on Wani-Bateshwar Trial Excavation, Journal of Bengal Art, v-5, pp. 283-298.

[5] Haque, M. M, Ahsan, S. M. K. \& Pawnkar, S.M. Pre-history of Bangladesh. Hossain, Md. Mosharraf, 1995, A Preliminary Study of the Pottery from Mahasthanganh, Journal of the Asiatic Society of Bangladesh, v-40(1), pp. 167-186.

[6] Jahan, Sahnaj Husne, Wari-Bateshwari: An important Centar of Maritime Activities in Ancient Bengal, Journal of Bengal Art, v-4, pp. 207-216.

[7] Karim, Rezaul, 1993, Wari-Bateshwarer Roupper Sapangkito Muddra: Akti Prostabona, Itihas, Sarobingsoti Borsho protho-tritio sonkha.

[8] Khan, F. A, 1991, Geology of Bangladesh, University Press Limited, Dhaka. Knudson, S. J, 1978, Culture in Retrospect, Boston.

[9] Khatun, Habiba, 1988. "Narshingdi juge juge, Smaronika", Jatio Seminar, Bangladesh Itihas Parishad, Narshingdi.

[10] Mansur, M. H, 7995. An Introduction to the Quaternary Geology of Bangladesh, City Press \& Publishers, Dhaka.

[11] Pathan, M. Habibulla, 1989, Pratnatattvik Nidarshan: Wari-Bateshwar. Report on Wari-BateshwarTrial Excavation, Journal of Bengal Art, v-5, pp. 283-298. 